\title{
Tidal variation of pulmonary blood flow and blood volume in piglets during mechanical ventilation during hyper-, normo- and hypovolaemia
}

\author{
Adrian Versprille, Jos R. C. Jansen \\ Pathophysiological Laboratory, Department of Pulmonary Diseases, Erasmus University, PO Box 1738, \\ NL-3000 DR Rotterdam, The Netherlands
}

Received August 24, 1992/Received after revision March 1, 1993/ Accepted March 10, 1993

\begin{abstract}
Effects of changes in blood volume on changes in pulmonary blood flow and pulmonary blood volume during the ventilatory cycle during mechanical ventilation with a positive end-expiratory pressure of $2 \mathrm{~cm} \mathrm{H}_{2} \mathrm{O}$ were determined in six pentobarbital anaesthetized, curarized pigs weighing about $10 \mathrm{~kg}$. Haemodynamic variables were analysed for each cardiac cycle in eight ventilatory cycles in four consecutive series under hyper-, normo- and hypovolaemic conditions. Cardiac output was highest in hypervolaemia. Compared with normo- and hypovolaemia, it decreased less during inflation, due to a smaller rise in central venous pressure and presumably a larger filling state of the venous system. The smaller decrease in right ventricular output in hypervolaemia coincided with a larger fall in transmural central venous pressure (right ventricular filling pressure), due to right ventricular action at a higher, less steep part of its function curve. The difference between right ventricular-output (electromagnetic flow measurement) and left ventricular-output (pulse contour) indicated changes in pulmonary blood volume. In hypervolaemia less blood shifted from the pulmonary circulation into the systemic system during inflation than in normo- and hypovolaemia. This difference can be explained by two mechanisms namely, the smaller fall in input into the pulmonary vascular beds and a smaller pulmonary vascular volume decrease as a result of transmural pressure fall at a steeper part of the pressure-volume curve.
\end{abstract}

Key words: Ventilatory cycle - Lung blood volume Cardiac output - Right ventricular function Hypervolaemia - Normovolaemia - Hypovolaemia Squeezing

\section{Introduction}

When spontaneous respiration is replaced by intermittent positive pressure ventilation, cardiac output is decreased.

Correspondence to: A. Versprille
This decrease has been attributed to a rise in intrathoracic pressure, and therefore an increase in central venous pressure $\left(P_{\mathrm{cv}}\right)$, during inflation. Inflation decreases right ventricular (RV) output, followed after a few beats by a decrease in left ventricular (LV) output $[1-3,5,9-12$, $18-22,24]$. As a consequence of the delayed decrease in LV output with respect to the fall in RV output, the blood volume of the pulmonary circulation $\left(Q_{\mathrm{p}}\right)$ will decrease during inflation. The tidal shift of blood from the pulmonary circulation into the systemic circulation and back increases if tidal volume increases $[19,22]$. The variation in $\mathrm{LV}$ flow is accompanied by a modulation of arterial pressure. This modulation is larger if blood volume is decreased [13], which could be explained either by corresponding changes in the variation of venous return to RV and LV, by changes in the amplitude of the tidal changes in pulmonary blood volume or by a combination of both mechanisms.

In this study, we have quantified the tidal changes in RV and LV output and the consequent tidal changes in $Q_{\mathrm{p}}$ during ventilatory cycles under hyper-, normo- and hypovolaemic conditions. Furthermore, we have evaluated cardiac function in the three volaemic conditions from the decrease in RV-filling pressure, i. e. transmural venous pressure $\left(P_{\mathrm{cv}, \mathrm{tm}}\right)$, during inflation, which coincided with a decrease in cardiac output.

\section{Methods}

Surgery. Six pigs $(8-10$ weeks old, weight $10.0 \pm 0.94 \mathrm{~kg}$ were anaesthetized with $30 \mathrm{mg} \mathrm{kg}^{-1} \mathrm{BW}$ (body weight) pentobarbitone sodium i. p. After cannulation of the external jugular vein anaesthesia was maintained by a continuous infusion of pentobarbitone sodium at $7.5-8.5 \mathrm{mg} \mathrm{kg}^{-1} \mathrm{~h}^{-1} \mathrm{BW}$. Such an infusion has been shown to maintain a constant pentobarbitone concentration in the blood throughout experiments of the same duration as those in this study [16]. After tracheotomy and during surgery the animals were ventilated at a rate of $40-50$ strokes per min. Tidal volume was adjusted to maintain end tidal $P_{\mathrm{CO} 2}$ at about $40 \mathrm{~mm} \mathrm{Hg}(5.3 \mathrm{kPa})$. End-expiratory pressure (PEEP) was set at $2 \mathrm{~cm} \mathrm{H}_{2} \mathrm{O}$ with the use of a water valve to avoid atelectasis. Expiratory $P_{\mathrm{CO}_{2}}$, airway pressure $\left(P_{\mathrm{T}}\right)$ and air flow $\left(V^{\prime}\right)$ were measured in the tracheal cannula 
and continuously monitored throughout the experiments. Body temperature was maintained at $38-39^{\circ} \mathrm{C}$ on a thermocontrolled operation table.

A catheter was inserted via the right common carotid artery into the aortic arch to obtain aortic pressure $\left(P_{\mathrm{ao}}\right)$. Two catheters were inserted through the external jugular vein: 1. A Swan Ganz catheter was placed into the pulmonary artery to measure pulmonary artery pressure $\left(P_{\mathrm{pa}}\right)$, to monitor central body temperature and to sample mixed venous blood for the estimation of cardiac output by means of the direct Fick method for oxygen. 2. A four-lumen catheter was inserted into the superior vena cava, one lumen to measure $P_{c r}$ another to infuse pentobarbitone sodium continuously and, a third to infuse tubo-curarine after surgery. Both catheters were fixed in the external jugular vein with two ligatures with viscous jelly in the vessel between the ligatures to avoid bleeding. The catheters for pressure measurements were kept patent with an infusion of $0.9 \% \mathrm{NaCl}$ solution at $3 \mathrm{ml} \mathrm{h}^{-1}$.

After thoracotomy through the second left intercostal space, an electromagnetic flow probe was positioned intrapericardially around the pulmonary artery. Two further catheters were placed in the pericardium, one filled with saline to measure pericardial pressure $\left(P_{\mathrm{it}}\right)$ and another to evacuate air and to restore negative pressure after closure of the pericardium and thorax. Another suction catheter was positioned in the thorax close to the vertebral spine. The thorax was sutured airtight and the stitches covered with vaseline. For about $1 \mathrm{~min}$ intrapericardial and intrathoracic suction was performed with a negative pressure of $10 \mathrm{~cm} \mathrm{H}_{2} \mathrm{O}$ $(1.0 \mathrm{kPa})$ supported by a PEEP of $10 \mathrm{~cm} \mathrm{H}_{2} \mathrm{O}$ to reverse the compression of parts of the left lung which had developed during surgery. To evacuate all air from the pericardium and thorax, we flushed saline into them through the catheter used for $P_{\text {it }}$ measurement until fluid could be sucked out without any air bubbles. We accounted for all fluid flushed into the animal. This procedure restored $P_{\mathrm{cv}}$ to its value before thoracotomy and so we assumed that the negative $P_{\text {it }}$, as measured at end-expiration, was the same as the unknown value before thoracotomy. The restored negative value at a PEEP of $2 \mathrm{cmH}_{2} \mathrm{O}$ and end-expiration in the ventilatory cycles did not change throughout the observation periods.

Measurements. The electrocardiogram (ECG) $P_{\mathrm{aog}}, P_{\mathrm{pa}}, P_{\mathrm{cy}}$ $(\mathrm{mm} \mathrm{Hg}), P_{\mathrm{T}}\left(\mathrm{cm} \mathrm{H}_{2} \mathrm{O}\right)$, pulmonary artery flow $\left(Q_{\mathrm{pa}}^{\prime}\right)$, airflow during inflation $\left(V_{\mathrm{I}}^{\prime}\right)$ and expiration $\left(V_{\mathrm{E}}^{\prime}\right)$ in arbitrary units were recorded continuously. Heart rate (HR) was calculated from the R$\mathrm{R}$ interval in the ECG. In the first two experiments $P_{\text {it }}(\mathrm{mm} \mathrm{Hg}$ ) was recorded occasionally using the pressure transducer used for the $P_{\mathrm{cv}}$ measurements, whereas in the last four experiments $P_{\mathrm{it}}$ was measured continuously. Transmural pressures (subscript "tm") were calculated by subtraction of $P_{\mathrm{i} r}$. The zero level of the blood pressures was set at the height of the manubrium by connection of the transducers to a reservoir filled with saline. Calibration was performed during application of pressure to the fluid level in the reservoir by comparison with a mercury manometer. The zero level of $P_{\mathrm{T}}$ was ambient air pressure; calibration was performed with a water manometer.

Inspiratory and mixed expiratory $\mathrm{O}_{2}$ and $\mathrm{CO}_{2}$ concentrations were measured by the use of a mass spectrometer (Perkin Elmer type MGA 1100). Acid-base balance, respiratory gas data and haemoglobin concentration were determined with a blood gas analyser (ABL3) and a haemoxymeter (OSM2) (both Radiometer, Copenhagen, Denmark). These respiratory and blood gas data were used to calculate cardiac output by means of the direct Fick method for oxygen.

Conditions during the observations. The anesthetized animals were paralysed with an infusion of d-tubocurarine at a rate of $0.2 \mathrm{mg} \mathrm{kg}^{-1} \mathrm{~h}^{-1}$, after a loading dose of $0.1 \mathrm{mg} \mathrm{kg}^{-1}$ in $3 \mathrm{~min}$. No deterioration in haemodynamic variables was observed.

After surgery, mechanical ventilation was performed using our computer-controlled ventilator [6] at a rate of 10 strokes per min. Tidal volume was re-adjusted to maintain arterial $P_{\mathrm{CO}_{2}}$ at about $40 \mathrm{~mm} \mathrm{Hg}$ and was not changed throughout the four series of ob- servations. Inspiration and expiration time were $2.4 \mathrm{~s}$ and $3.6 \mathrm{~s}$ respectively.

Protocol and observations. After a stabilization period of $30-$ $45 \mathrm{~min}$, four similar series of observations were performed, each under a different volaemic condition. A series of observations took about $1 \mathrm{~h} 15 \mathrm{~min}$ and started with two estimations of cardiac output using the direct Fick method for oxygen (except in the first two experiments where only one estimate of cardiac output was made). The two estimates were then averaged. Subsequently, four computer samples of the haemodynamic variables during three ventilatory cycles $(18 \mathrm{~s})$ were taken at intervals of $1 \mathrm{~min}$. Next, for other reasons, seven inspiratory hold procedures were performed at intervals of $5 \mathrm{~min}$ [20]. Thereafter the haemodynamic data of three ventilatory cycles were samples four times. The series of observations was ended after another pair of cardiac output determinations using the Fick method, except in the first two experiments where again only one determination was made. The first series was performed under conditions of normal blood volume and normal blood composition and is called normovolaemia- 1 . Then, a series followed under hypervolaemic conditions: blood volume was increased with $15 \mathrm{ml}$ dextran solution per $\mathrm{kg} \mathrm{BW}$ (Rheomacro-dex ${ }^{2}$ ) which was infused over about $10 \mathrm{~min}$ via either the central venous or the arterial catheter. Observations were started $5 \mathrm{~min}$ after the end of the infusion. After this hypervolaemic series, normovolaemia was restored by bleeding $15 \mathrm{ml} \mathrm{kg}{ }^{-1}$ $\mathrm{BW}$ over about $10 \mathrm{~min}$. After this normovolaemia-2 series which, because the haemodilution, differed from the first series, another bleeding ( $15 \mathrm{ml} \mathrm{kg}^{-1} \mathrm{BW}$ ) established hypovolaemia.

The four different volaemic series were performed in the same sequence in all six animals. To avoid post-reinfusion haemodynamic responses to substances released, for example from thrombocytes, during storage of autologous blood outside the body, we did not randomize the volaemic conditions. To assess whether a systematic bias on the results was exerted by the constant sequence of volaemic conditions, e. g., whether the animal's condition deriorated, we compared haemodynamic data at the beginning and end of each series. We also tested for differences between the two normovolaemic series.

After all series the animals were sacrificed by administration of an overdose of pentobarbitone. Post-mortem examination was performed to verify the position of catheters and to examine the condition of airways and alveolar areas. Autopsy did not reveal any reasons for rejecting any experiments.

Acquisition and analysis of haemodynamic data. All signals were recorded continuously throughout the experiments on a chart recorder (Hewlett Packard, type 7700). Numerical analysis of ECG, blood pressures and blood flow was performed by computer (PDP $11 / 23$, Digital Equipment Corporation) sampling at a rate of $250 \mathrm{~Hz}$ over periods of $18 \mathrm{~s}$. These special observations were backed up by simultaneous analogue data recording on electromagnetic tape (Racall, type Store 14). Blood pressures were automatically averaged per cardiac cycle, based on the R-R-interval of the ECG. Flow and pulse contour curves were calibrated off-line after each experiment. The areas under the $Q_{\mathrm{pa}}$ were analysed by hair-line positioning on a monitor [20]. The area under one flow curve represented RV stroke volume. LV stroke volume was obtained from the pulse contour of the $P_{\text {ao }}$ curve [23] again with use of hair-line analysis. Diastolic $P_{\text {ao }}$ fluctuated during each ventilatory cycle, implying a drift in the baseline of the pulse contour area. We corrected for this drift by using as the baseline the straight line connecting the two diastolic pressures on either side of a pulse contour wave.

Flow and pulse contour curves were calibrated by summation of the areas under all heart beats during two ventilatory cycles and dividing each total area by the total interval time, giving area units per second $\left(\mathrm{AUs}^{-1}\right)$. This value was divided by cardiac output in $\mathrm{ml} \mathrm{s}{ }^{-1}$, obtained from the direct Fick method for oxygen, giving calibration factors in $\mathrm{AU} / \mathrm{ml}$ for flow and pulse contour respectively. Stroke volume $(\mathrm{ml})$ was obtained from the area of one heart 
beat $(\mathrm{AU})$ divided by the calibration factor $\left(\mathrm{AU} \mathrm{ml}^{-1}\right)$. Stroke volume $(\mathrm{ml})$ divided by heart interval(s) produced flow $\left(\mathrm{ml} \mathrm{s}^{-1}\right)$ per cardiac cycle. In a previous study, we have validated the reliability of the pulse contour under conditions of mechanical ventilation [22].

Haemodynamic signals were obtained from three consecutive ventilatory cycles $(18 \mathrm{~s})$, starting at the beginning of expiration in the first cycle. Variables were sampled four times at intervals of $1 \mathrm{~min}$. From each sampling period, two full ventilatory cycles were analysed, giving data from two times 8 cycles per series of observations. The data at the beginning of an observation period were used for comparison between the volaemic conditions. The data at the end of an observation period were used as a control for evaluation of stability throughout the period of a volaemic condition by comparison with the data at the beginning of that period.

Tidal loss in flow during inflation was calculated for both $Q_{\mathrm{rv}}^{\prime}$ and $Q_{\text {Iv }}^{\prime}$, as previously reported [22]. This tidal loss served as a measure of flow fluctuation. The tidal loss of $Q_{\mathrm{rv}}^{\prime}$ was obtained from the difference between each beat in the ventilatory cycle and the averaged value of the last three beats at end-expiration of the preceding cycle. These differences were negative during inflation and became positive during early expiration. All differences were summed and averaged per cycle. They were expressed in $\mathrm{ml} \mathrm{s}^{-1}$ and as a percentage of end-expiratory flow. This overall difference actually indicate the difference between the end-expiratory flow and the mean flow during the ventilatory cycle. For the calculation of tidal loss in $Q_{\text {lv }}^{\prime}$ we applied the same procedure, except that two end-expiratory beats were used for the calculation of end-expiratory flow.

Changes in $Q_{\text {lv }}^{\prime}$ in early inflation were studied in the first four heart beats during inflation. The percentage difference was calculated between the mean output of the first and the second pair of beats and that of the last two beats in the preceding end-expiratory period. We also determined the percentage change in output of the second pair compared with that of the first pair. Averages of two beats were taken to smooth slight fluctuations in the output of successive beats.

Tidal shift of blood volume between the pulmonary circulation and the systemic circulation was estimated from the differences between RV and LV stroke volumes. These differences were negative during inflation, indicating a shift of blood from lung circulation into systemic circulation. During expiration the differences were positive, indicating recovery of pulmonary blood volume. At end expiration both stroke volumes were the same.

In each series of observations, eight values of tidal loss in flow and eight values of blood shift were obtained. Averages and standard deviations were calculated in each animal. We calculated power of RV heart beats $\left(W_{\mathrm{rv}}\right)$ during a ventilatory cycle. $W_{\mathrm{rv}}$ $\left(\mathrm{mm} \mathrm{Hg} \mathrm{ml} \mathrm{s} \mathrm{s}^{-1}\right)$ was obtained from flow per beat $\left(\mathrm{ml} \mathrm{s}^{-1}\right)$ and transmural pulmonary artery pressure $\left(P_{\mathrm{pa} \text {. tn }}\right)$. To compare RV function in the three volaemic conditions, cardiac function curves [15] were made by plotting $W_{\mathrm{rv}}$ against $P_{\mathrm{cr}, \mathrm{tm}}$ as a representation of RV filling pressure.

Statistical analyses. Two tests were mainly used for comparison of data: Student's $t$-test for paired samples (one-sample analysis) and Student's $t$-test for independent samples (two-sample analysis). Data were regarded as significantly different at $P<0.05$. Where appropriate, data are given as mean $\pm \mathrm{SD}$.

\section{Results}

\section{Body temperature}

At the start of the observations and after surgery body temperature was $38.4 \pm 1.2^{\circ} \mathrm{C}$ and $38.8 \pm 0.7^{\circ} \mathrm{C}$ at the end of the experiments; this difference was not significant $(P=0.39)$.

\section{Stability throughout each series}

In Table 1 we present data of cardiac output obtained by the Fick method and measurements of $P_{\mathrm{ao}}, P_{\mathrm{pa}}, P_{\mathrm{cv}}$ and $\mathrm{HR}$, averaged over a ventilatory cycle at the beginning and at the end of an observation series. In the two normovolaemic series and in the hypovolaemic series no significant changes in the haemodynamic variables occurred. Throughout the hypervolaemic series, $P_{\mathrm{pa}}$ and $P_{\mathrm{cv}}$ decreased significantly, while cardiac output did not change significantly $(P=0.082)$. Cardiac output decreased in four animals, in one it remained the same and in the other it increased. HR did not change significantly throughout the hypervolaemic series.

\section{Differences between the series}

No differences were observed between the variables in the two normovolaemic series (Table 1). Cardiac output and all blood pressures increased significantly in hypervolaemia compared with normovolaemia-1. HR did not change. Although in five out of six experiments cardiac output was larger in the hypervolaemic series than in normovolaemia-2, the overall difference between the two series did not reach significance $(P=0.058)$. On changing the condition from hyper to normovolaemia2 all blood pressures decreased and HR increased. In hypovolaemia, HR was increased and all other variables were decreased compared with hypervolaemia and, except for $\mathrm{HR}$ and $P_{\text {pa }}$, also with respect to normovolaemia-2.

\section{Pattern of haemodynamic changes}

The pattern of haemodynamic changes during a ventilatory cycle are illustrated as an individual example in Fig. 1. The changes in $P_{\mathrm{ao}}, P_{\mathrm{ao}, \mathrm{tm}}, P_{\mathrm{pa}}$ and $P_{\mathrm{pa}, \mathrm{tm}}$ (Fig. $\left.1 \mathrm{a}\right)$, $Q_{\mathrm{rv}}^{\prime}$ and $Q_{\mathrm{lv}}^{\prime}$ (Fig. 1b), $P_{\mathrm{cv}}, P_{\mathrm{cv}, \mathrm{tm}}$ and $P_{\mathrm{it}}$ (Fig. 1c) and the changes in $Q_{\mathrm{p}}$.(Fig. 1d) are presented for the conditions of normovolaemia-2. The haemodynamic variables, averaged per cardiac cycle, were plotted at the time of the R-wave in the ECG at the start of the corresponding cardiac cycle, except for $P_{\mathrm{it}}, P_{\mathrm{cv}}$ and $P_{\mathrm{cv}, \mathrm{tm}}$, which were plotted at the end of the cardiac cycle. This assured a relation of $Q_{\mathrm{rv}}^{\prime}$ with filling pressure, represented by $P_{\mathrm{cv}, \mathrm{tm}}$, measured during the preceding cardiac cycle. In Figs. $2 a-d$ and $3 a-d$ the corresponding data observed in conditions of hypervolaemia and hypovolaemia respectively are presented. The pattern of changes in normovolaemia- 1 was much the same as that in normovolaemia- 2 .

In normovolaemia, the typical pattern of changes during inflation and expiration is observed, as reported previously $[19,22] . P_{c v}$ increased during inflation and recovered in early expiration (Fig. 1c). This increase was less than that in $P_{\mathrm{it}}$, leading to a fall in $P_{\mathrm{cv}, \mathrm{tm}}$. RV output decreased from the start of inflation and increased, after an overshoot in early expiration, to an endexpiratory stationary level (Fig. 1 b). LV output followed 
Table 1. Haemodynamic values in all series

\begin{tabular}{|c|c|c|c|c|c|c|}
\hline & & $\begin{array}{l}Q^{\prime} \\
\mathrm{mls}^{-1} \mathrm{~kg}^{-1}\end{array}$ & $\begin{array}{l}P_{\mathrm{ao}} \\
\mathrm{mm} \mathrm{Hg}\end{array}$ & $\begin{array}{l}P_{\mathrm{pa}} \\
\mathrm{mm} \mathrm{Hg}\end{array}$ & $\begin{array}{l}P_{\mathrm{cv}} \\
\mathrm{mm} \mathrm{Hg}\end{array}$ & $\begin{array}{l}\mathrm{HR} \\
\mathrm{b} / \mathrm{min}\end{array}$ \\
\hline $\begin{array}{l}\text { Normo- } \\
\text { volaemia-1 }\end{array}$ & $\mathrm{s}$ & $\begin{array}{l}2.06 \pm 0.41 \\
2.04 \pm 0.55\end{array}$ & $\begin{array}{l}75 \pm 10 \\
79 \pm 13\end{array}$ & $\begin{array}{l}12 \pm 1.8 \\
13 \pm 2.2\end{array}$ & $\begin{array}{l}1.7 \pm 1.1 \\
1.6 \pm 1.2\end{array}$ & $\begin{array}{l}140 \pm 35 \\
151 \pm 43\end{array}$ \\
\hline $\begin{array}{l}\text { Hyper- } \\
\text { volaemia }\end{array}$ & $\begin{array}{l}\mathrm{s} \\
\mathrm{e}\end{array}$ & $\begin{array}{l}2.90 \pm 0.82 \\
2.71 \pm 0.72\end{array}$ & $\begin{array}{l}90 \pm 16 \\
87 \pm 13\end{array}$ & $\begin{array}{l}19 \pm 3.1 * \\
16 \pm 3.4\end{array}$ & $\begin{array}{l}4.51 \pm 1.6^{*} \\
2.4 \pm 0.8\end{array}$ & $\begin{array}{l}144 \pm 31 \\
152 \pm 37\end{array}$ \\
\hline $\begin{array}{l}\text { Normo- } \\
\text { volaemia-2 }\end{array}$ & $\begin{array}{l}\mathrm{s} \\
\mathrm{e}\end{array}$ & $\begin{array}{l}2.19 \pm 0.38 \\
2.11 \pm 0.23\end{array}$ & $\begin{array}{l}80 \pm 14 \\
80 \pm 11\end{array}$ & $\begin{array}{l}13 \pm 2.2 \\
14 \pm 1.8\end{array}$ & $\begin{array}{l}1.1 \pm 1.0 \\
1.2 \pm 1.0\end{array}$ & $\begin{array}{l}166 \pm 30 \\
170 \pm 28\end{array}$ \\
\hline $\begin{array}{l}\text { Hypo- } \\
\text { volaemia }\end{array}$ & $\begin{array}{l}\mathrm{s} \\
\mathrm{e}\end{array}$ & $\begin{array}{l}1.46 \pm 0.40 \\
1.48 \pm 0.38 \\
\end{array}$ & $\begin{array}{l}70 \pm 10 \\
68 \pm 10 \\
\end{array}$ & $\begin{array}{l}12 \pm 2.1 \\
12 \pm 1.6 \\
\end{array}$ & $\begin{array}{l}0.0 \pm 1.3 \\
0.3 \pm 1.1 \\
\end{array}$ & $\begin{array}{l}194 \pm 23 \\
195 \pm 10\end{array}$ \\
\hline $\begin{array}{l}\text { Normo-1 vs Hypervol: } \\
\text { Normo-1 vs Normo-2: } \\
\text { Normo-2 vs Hypervol: } \\
\text { Normo-2 vs Hypovol: } \\
\text { Hypervol vs Hypovol: }\end{array}$ & & $\begin{array}{l}<0.05 \\
\text { ns } \\
\text { ns } \\
<0.001 \\
<0.02\end{array}$ & $\begin{array}{l}<0.02 \\
\mathrm{~ns} \\
<0.01 \\
<0.05 \\
<0.02\end{array}$ & $\begin{array}{l}<0.001 \\
\mathrm{~ns} \\
<0.001 \\
\mathrm{~ns} \\
<0.005\end{array}$ & $\begin{array}{l}<0.03 \\
\mathrm{~ns} \\
<0.02 \\
<0.01 \\
<0.01\end{array}$ & $\begin{array}{l}\text { ns } \\
\text { ns } \\
<0.04 \\
\text { ns } \\
<0.04\end{array}$ \\
\hline
\end{tabular}

$Q^{\prime}$, Cardiac output; $P_{\text {ao }}$, aortic pressure; $P_{\mathrm{pa}}$, pulmonary artery pressure; $P_{\mathrm{cm}}$ central venous pressure; HR, heart rate; $\mathrm{s}$, start of a series; e end of a series. Values are means $\pm \mathrm{SD}, n=6$ pigs; $* P<0.01$ start vs end, paired $t$-test

the changes in RV output with a delay of a few beats, but never showed an overshoot during recovery. $P_{\text {ao }}$ changed in parallel with LV output (Fig. 1a). $P_{\text {ao, tru }}$ showed the same pattern of changes as $P_{\text {ao }}$ due to the relatively small changes in $P_{\text {it }}$ (note the difference in pressure scaling). $P_{\mathrm{pa}}$ hardly changed during inflation and fell below end-expiratory level in early expiration, followed by recovery. $P_{\mathrm{pa}, \mathrm{tm}}$ decreased gradually but slightly during inflation and recovered during expiration. The pattern of changes in volume flow per cardiac cycle (Fig. 1b) is like the pattern of stroke volumes reported previously [22]. The reason is that heart interval changed by less than $3 \%$ within a ventilatory cycle.

$Q_{\mathrm{p}}$ decreased during inflation and recovered during expiration. The tidal shift of blood from the pulmonary circulation into the systemic circulation is indicated by the negative values of the differences between RV and LV stroke volumes (Fig. 1d). Recovery is indicated by the positive values.

In hypervolaemia (Fig. $2 a-d$ ) the following striking differences were observed compared with normovolaemia-2 (Figs. $1 \mathrm{a}-\mathrm{d}$ ):

1. In this individual example, cardiac output was higher than in normovolaemia-2, as it was in the majority of animals, as mentioned above.

2. $Q_{\mathrm{rv}}^{\prime}, Q_{\mathrm{lv}}^{\prime}$ and $P_{\text {ao }}$ decreased less during inflation.

3. The decrease in $P_{\mathrm{cv}, \mathrm{tm}}$ was larger in spite of a smaller fall in RV output.

4. The rise in $P_{\mathrm{pa}}$ was larger during inflation and the fall during expiration took it to barely below endexpiratory level.

5. The tidal shift of blood from the pulmonary circulation into the systemic circulation was smaller.

6. The delay in the fall of $Q_{\mathrm{lv}}^{\prime}$ from the start of inflation was longer. During this delay output was at or above the end-expiratory level.

The slightly larger rise in $P_{\text {it }}$ during inflation in this example is not typical for all experiments, because we found no statistical differences in the rise of $P_{\mathrm{it}}$ between the four volaemic series in the four experiments in which we continuously recorded $P_{\text {it }}(P=0.43$, paired $t$-test between hypervolaemia and normovolaemia-2).

In hypovolaemia (Fig. 3a-d) the changes were about the same as those in normovolaemia. $P_{\mathrm{ao}}, Q_{\mathrm{ry}}^{\prime}$ and $Q^{\prime}{ }_{\text {iv }}$ were all lower than in normovolaemia. The pattern of the changes during the ventilatory cycle and their amplitude were similar to those in normovolaemia. The rise in $P_{\mathrm{cv}}$ and the decrease in $P_{\mathrm{cv}, \mathrm{tm}}$ during inflation were about the same as those in normovolaemia.

\section{$R V$ function}

In Fig. 4 , the $W_{\mathrm{rv}}$ is plotted against $P_{\mathrm{cv}, \text { tm }}$ during a ventilatory cycle in hyper-, normo- and hypovolaemia. The data points were obtained from the same individual results as presented in Figs. 1-3. The power/filling pressure relation in hypovolaemia is shifted slightly to the right compared with normovolaemia. In hypervolaemia the relation is less steep and at higher levels of $W_{\mathrm{rv}}$ and $P_{\mathrm{cv}, \mathrm{tm}}$.

\section{Tidal loss in ventricular output and the rise in $P_{c v}$}

The tidal loss in flow is presented in Table 2 for all volaemic conditions. In each of the volaemic conditions, the tidal loss in RV output and that in LV output were similar so that only the data for tidal loss in RV output are presented.

Tidal loss in flow, calculated as a percentage of endexpiratory flow, was significantly smaller in hypervolaemia than in normovolaemia. In hypovolaemia, tidal loss in flow as a percentage was significantly larger. There was no significant difference between the two normovolaemic conditions. The tidal loss expressed in $\mathrm{ml} \mathrm{s}^{-1} \mathrm{~kg}^{-1}$ BW was significantly smaller in hypervolaemia than in normovolaemia-2, but in hypovolaemia it was similar to 
Pao and Ppa

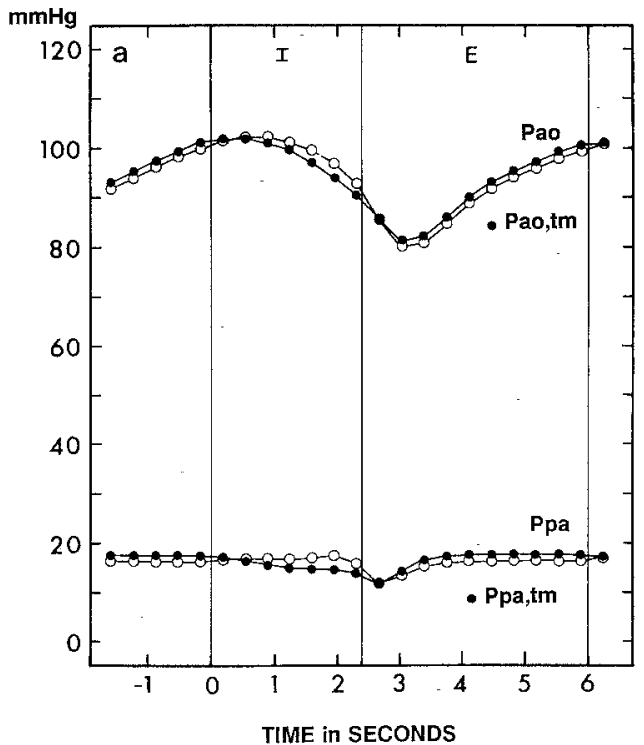

Pcv and Pit

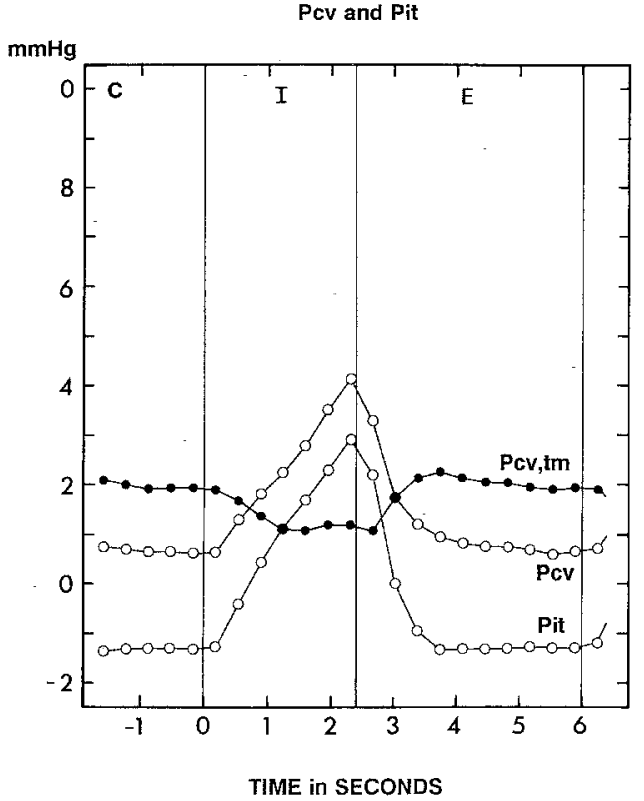

RV and LV OUTPUT
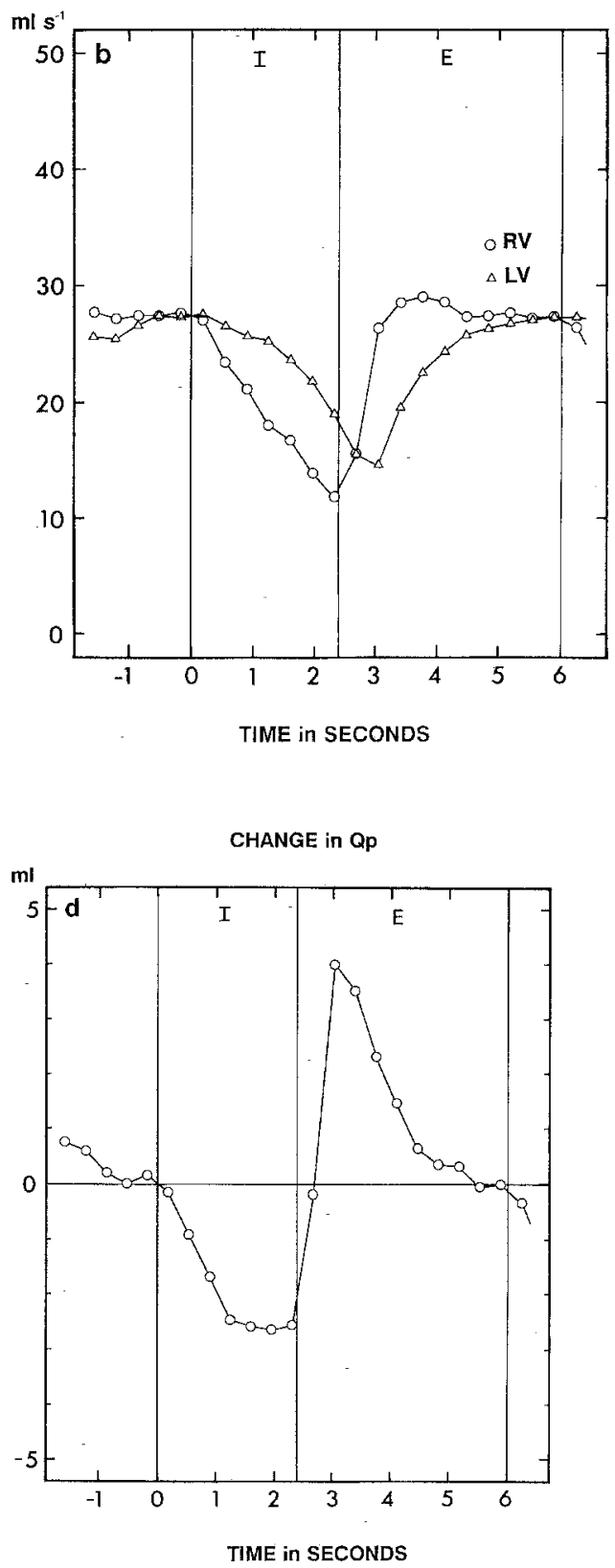

Fig. 1a-d. Individual example of beat-to-beat changes in haemodynamic variables during a ventilatory cycle in normovolaemia-2. All $\mathrm{X}$ axes are time in $\mathrm{s}$. Zero time is start of inflation $(I)$. At $2.4 \mathrm{~s}$ expiration $(E)$ begins and lasts until $6 \mathrm{~s}$. (Negative time is part of the preceding ventilatory cycle). a The changes in aortic pressure $\left(P_{\text {ao }}\right)$, and pulmonary artery pressure (open symbols) $\left(P_{\mathrm{pa}}\right) ; P_{\mathrm{ao}, \mathrm{tm}}$ and $P_{\mathrm{pa}, \mathrm{m}}$ are the respective transmural pressures (closed symbols). b Changes in right ventricle $(R V, O)$ and left ventricle $(L V, \triangle)$ output. c Changes in central nervous $\left(P_{\mathrm{cv}}\right)$ and $\left(P_{\mathrm{it}}\right)$ the intrathoracic pressure, actually intrapericardial pressure (open symbols) transmural central venous pressure $\left(P_{\mathrm{cv}, \mathrm{tm}}\right.$, closed symbols). d Change in pulmonary blood volume $\left(Q_{\mathrm{p}}\right)$. Zero-value of $Q_{\mathrm{p}}$ is volume at end-expiration (unknown) that in normovolaemia-2. In normovolaemia-2, tidal loss in flow was slightly but significantly larger than in the first normovolaemic series.

Because the decrease in venous return is attributed to the rise in $P_{\mathrm{cv}}$, we also averaged the rise in $P_{\mathrm{cv}}$ in all four volaemic conditions. The rise in $P_{\mathrm{cv}}$ during inflation is significantly smaller in hypervolaemia than in the other volaemic conditions. The difference is on average $0.9 \mathrm{~mm} \mathrm{Hg}$.

\section{Changes in LV output during early inflation}

In normovolaemia-1 $Q_{\text {lv }}^{\prime}$ was slightly but significantly increased during the first pair of beats in inflation compared with output at end-expiration. No significant dif- ference existed between the output of the second pair and end-expiratory output (Table 3 ).

In the hypervolaemic series, cardiac output increased immediately after the start of inflation. This rise was even larger in the second pair of beats. In normovolaemia-2, no change was found in the first pair of beats, whereas the second pair showed a decreased output. In hypovolaemia, the first two beats also produced an output similar to that of the end-expiratory beats. During the second two beats in inflation, flow was significantly more decreased in hypovolaemia than that in normovolaemia.

\section{Changes in $Q_{p}$}

The amount of pulmonary blood which shifted into the systemic circulation during inflation and the amount 
Pao and Ppa

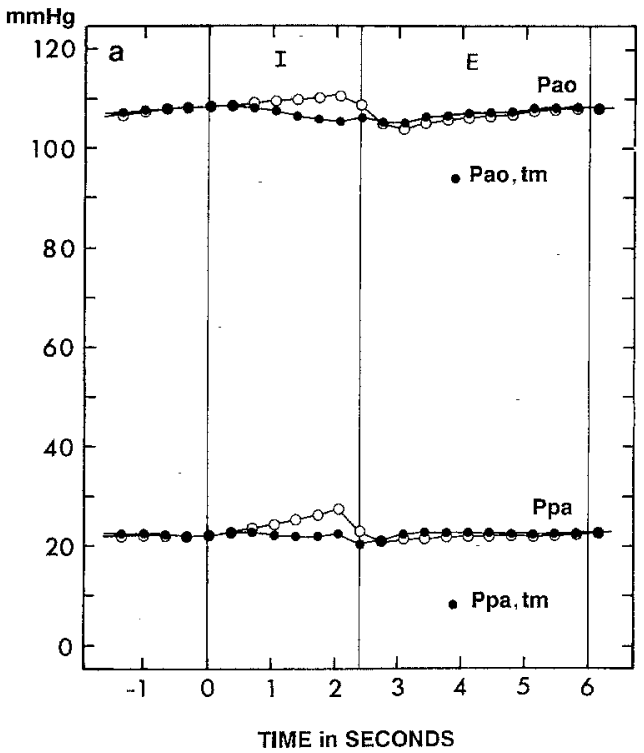

Pcv and Pit

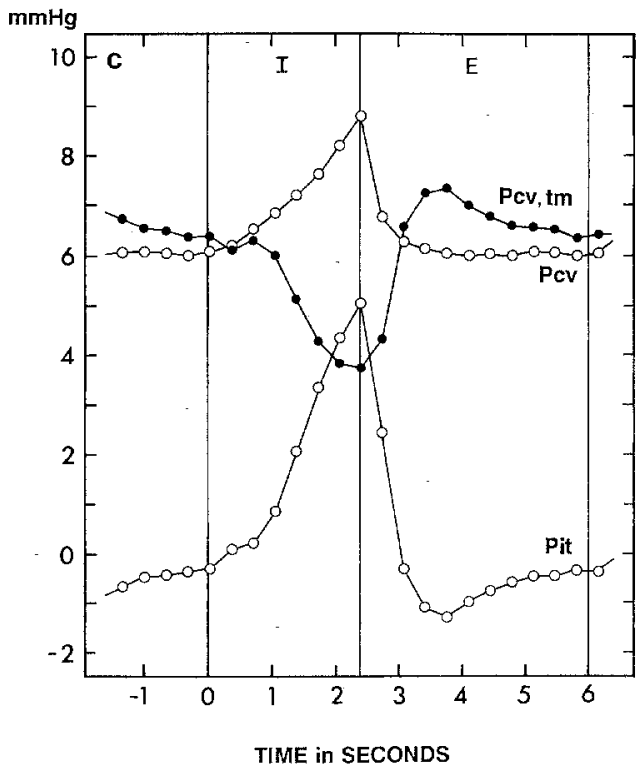

RV and LV OUTPUT
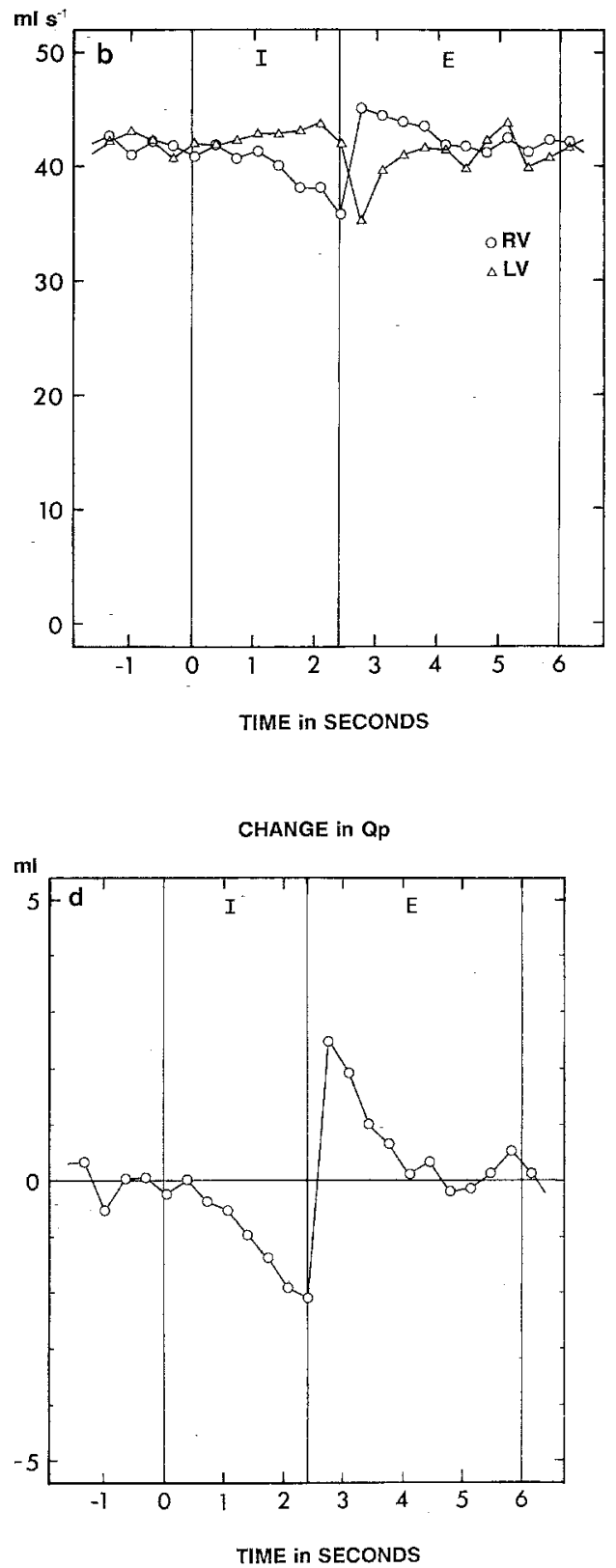

Fig. 2a-d. Beat-to-beat changes in haemodynamic variables during a ventilatory cycle in hypovolaemia, obtained from the same animal as in Fig. 1. Details as in Fig. 1 which shifted back during expiration were similar. The $P$ values were $0.16-0.98$ (paired $t$-tests in the four volaemic series, $n=48$ per series). Therefore, we only present the shift of pulmonary blood from the pulmonary circulation into the systemic circulation during inflation in Table 4. In hypervolaemia, the shift was significantly smaller than that in normovolaemia-2. No differences were found between normovolaemia-1, normovolaemia2 and hypovolaemia.

\section{Discussion}

\section{The protocol}

This study was performed using a systematic order of conditions, which could have biased the results. For four reasons we believe the order of observations not to have had any significant influence on our results. First, in the two normovolaemic series, the majority of haemodynamic values were the same (Table 1). The only differences between the two normovolaemic series were a slightly smaller tidal loss in flow in normovolaemia-1 (Table 2), and a slight increase in LV output during the first pair of beats in inflation in normovolaemia-1, whereas in normovolaemia-2 no change occurred (Table 3). Second, the hypervolaemic series was between these two similar normovolaemic series, which eliminates biased results in the hypervolaemic series other than those due to volume loading. Third, the differences in cardiac output between the three volaemic conditions agree with those observed by Morgan et al. [11], who worked in the opposite order. Fourth, in the two 
Pao and Ppa

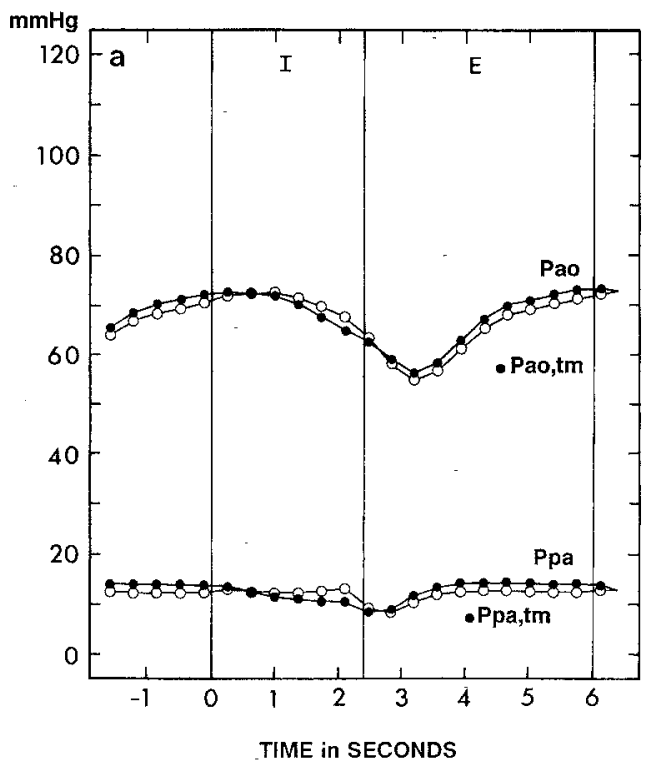

Pcy and Pit

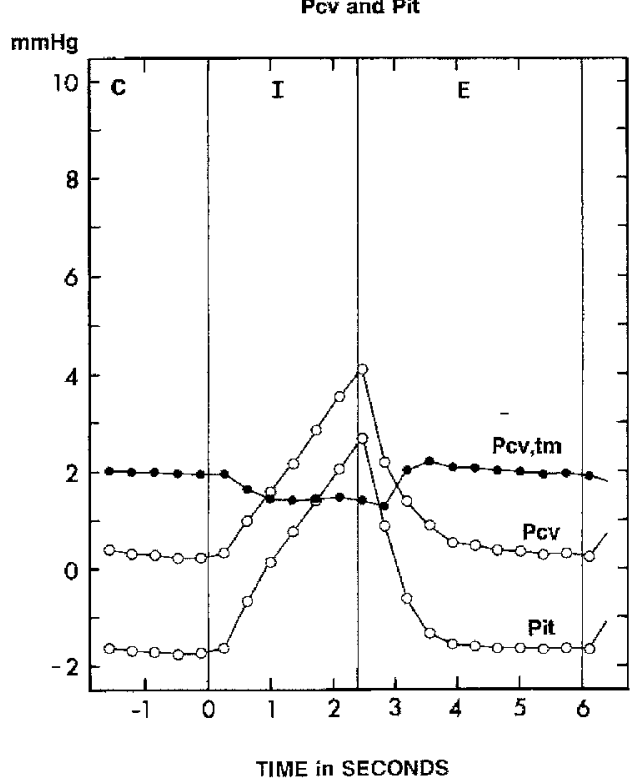

RV and LV OUTPUT

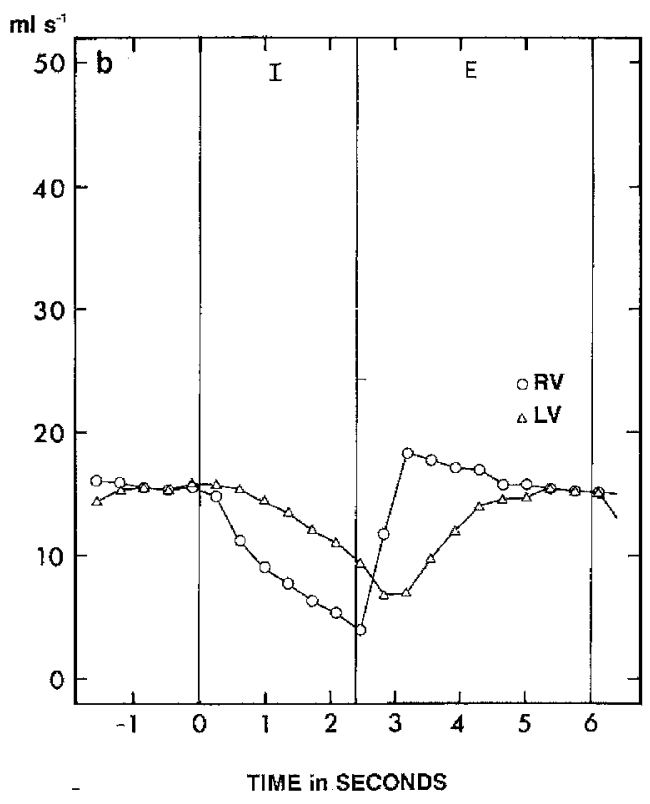

CHANGE in Qp

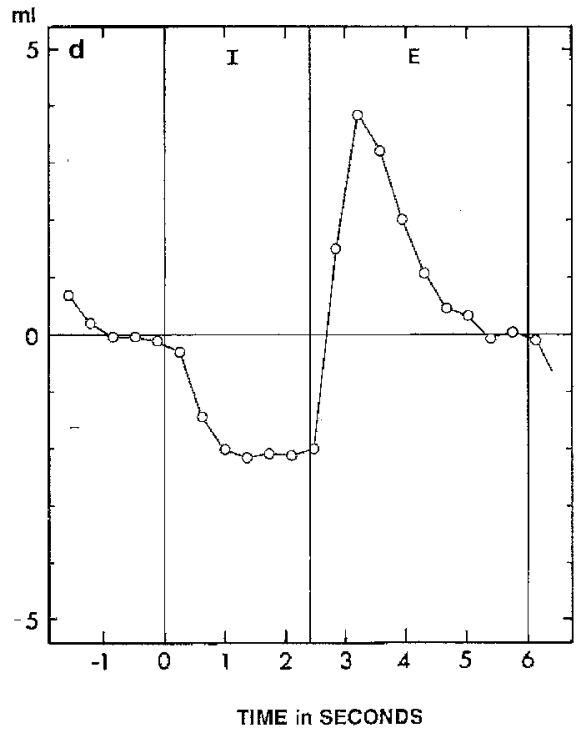

Fig. 3a-d. Beat-to-beat changes in haemodynamic variables during a ventilatory cycle in hypovolaemia, obtained from the same animal as in Fig. 1. Details as in Fig. 1 normovolaemic series and the hypovolaemic series all haemodynamic variables were the same at start and end, indicating stable conditions throughout each series over a period of more than an hour. Considering these points, we conclude that our results would not have been different if the hypovolaemic series was performed between the two normovolaemic series with the hypervolaemic series last.

\section{Changes during the hypervollaemic series}

In the hypervolaemic series, some changes over time were observed. $P_{\mathrm{pa}}$ and $P_{\mathrm{cv}}$ were significantly lower at the end of the series than at the start (Table 1). Although cardiac output was also about $7 \%$ lower at the end than at the beginning, this difference failed to reach signifi- cance. The variable which did not change was arterial pressure. Arterial pressure is a well-controlled variable. In spite of a relatively large increase in cardiac output, followed by a decrease to baseline values in little more than an hour, arterial pressure remained within narrow limits [25]. The duration of hypervolaemia in our experiments corresponded with this time period.

The question may be posed why cardiac output did not decrease more after the establishment of hypervolaemia in our experiments? If, during mechanical ventilation cardiac output and other haemodynamic variables are below the normal values seen during spontaneous respiration, stimuli which lead to a cardiac output decrease are probably ineffective. Perhaps, in our present study, loading of the circulation caused cardiac output to recover to various levels below, at or above the normal value before mechanical ventilation. If recovery of car- 


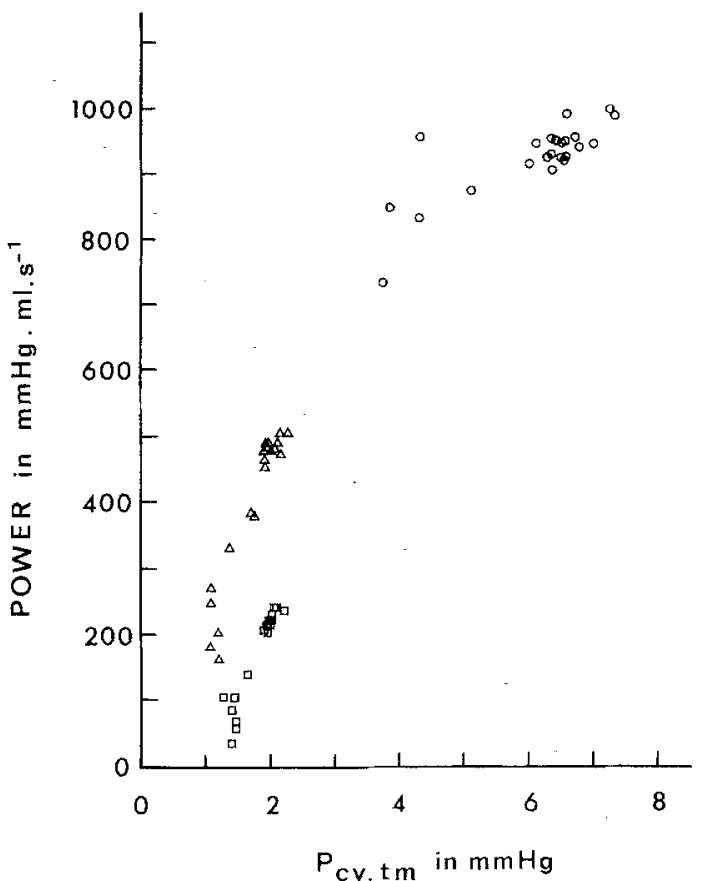

Fig. 4. RV function (power/filling pressure) curves, obtained from the data in Figs. 1-3. Power is expressed in standard units. RV filling pressure is taken as $P_{\mathrm{cv}, \mathrm{m}}$. Circles data from Fig. 2, (hypervolaemia); triangles data from Fig. 1 (normovolaemia-2); squares data from Fig. 3 (hypovolaemia)

diac output occurred to a level below or at the normal value, hardly any stimuli might have been present to cause a decrease in cardiac output. Such possible differences in indiviual responses on volume loading under conditions of mechanical ventilation might explain the non-significant change in cardiac output throughout the hypervolaemic series.

\section{Haemodynamic changes during a ventilatory cycle}

Pattern of changes. The haemodynamic changes during a ventilatory cycle have been extensively reported in the literature (see Introduction). Our data in normovolaemia confirmed these results. Therefore, we will mainly consider the differences between the different volaemic conditions.

\section{$R V$ output and $R V$ filling pressure}

Why did a small decrease in RV output during inflation coincide with a relatively large decrease in filling pressure (i. e., $P_{\mathrm{cv}, \mathrm{tm}}$ ) in hypervolaemia (Fig. $2 \mathrm{~b}-\mathrm{c}$ ), whereas in normo- and hypovolaemia a large fall in RV output coincided with a relatively small decrease in $P_{\mathrm{cv}, \mathrm{m}}$ (Figs. 1 and $3 b-c$ ). The answer is found in the data for RV function (Fig. 4). When inflation caused a fall in venous return, and therefore $Q_{\mathrm{rv}}^{\prime}$, due to $P_{\mathrm{cv}}$ rising as a consequence of the rise in $P_{\text {it }}$, it also caused a slight decrease in $P_{\mathrm{pa}, \mathrm{m}}$, implying that the fall in $W_{\mathrm{rv}}$ was slightly larger than the fall in RV output. Therefore, we plotted $W_{\mathrm{rv}}$ instead of RV output versus $P_{\mathrm{cv}, \mathrm{tm}}$. In hypervolaemia, the fall in $W_{\mathrm{rv}}$ during inflation was smallest but the fall in $P_{\mathrm{cv}, t \mathrm{~m}}$ of the RV was largest. Apparently, the circulation was filled to such an extent that the RV acted in the upper part of its power/filling pressure relationship. In normo- and hypovolaemia, RV action was restricted to the steepest, lower part of that relation. We have no definite explanation for the slight shift of the power/filling pressure relation to a higher values of $P_{\mathrm{cv}, \text { tr }}$ in hypovolaemia compared with normovolaemia2 . It might be that the lower $P_{\text {ao }}$ in hypovolaemia reduced perfusion of the coronary system and therefore reduced cardiac contractility.

\section{Tidal loss in flow}

Because the end-expiratory output of the ventricles is stable, it can be regarded as a baseline condition for the tidal flow changes during a ventilatory cycle during mechanical ventilation $[18,21]$. The decrease in RV output during inflation by accumulation of blood in the venous system $[19,20,22]$ is greater than the recovery during expiration (Figs. 1-3, b), leading to a tidal loss in flow. We attributed this smaller recovery of flow, when the venous capacities are emptied again, to the low arterial pressure [20], causing a decreased flow of blood into the venous system corresponding to the LV output (Fig. 1-3, a and b). Blood flow coming from the unloading venous capacities added to the low flow from the arterial into the venous system does not compensate quantitatively during expiration for the fall in flow occurring during inflation.

Table 2. Tidal loss in right ventricular flow and tidal rise in $P_{\mathrm{cv}}$ during inflation

\begin{tabular}{|c|c|c|c|c|c|c|}
\hline & \multicolumn{4}{|c|}{ RV flow loss } & \multirow{2}{*}{\multicolumn{2}{|c|}{$\frac{\text { Rise in } P_{\mathrm{cv}}}{\mathrm{mm} \mathrm{Hg}}$}} \\
\hline & \multicolumn{2}{|c|}{$\%$ of end-exp flow } & \multicolumn{2}{|l|}{$\mathrm{ml} \cdot \mathrm{s}^{-1} \cdot \mathrm{kg}^{-1}$} & & \\
\hline Normovolaemia-1 & $9.0 \pm 3.0$ & 0.15 & $0.20 \pm 0.084$ & 0.050 & $2.6 \pm 0.39$ & 0.90 \\
\hline Hypervolaemia & $2.2 \pm 2.0$ & 0.002 & $0.060 \pm 0.065$ & 0.005 & $1.7 \pm 0.66$ & 0.000 \\
\hline
\end{tabular}

Values are means $\pm \mathrm{SD}, n=48$ in all volaemic series. $P$, probability value from paired $t$-test vs. normovolaemia- 2 RV, right ventricle 
Table 3. Percentage change in left ventricular output during inflation

\begin{tabular}{llllr}
\hline & Normovol. 1 & Hypervol. & Normovol. 2 & Hypovol. \\
\hline Pair 1 & $1.9 \pm 4.2 *$ & $1.0 \pm 2.6^{* *}$ & $-0.6 \pm 2.3$ & $0.4 \pm 2.7$ \\
Pair 2 & $-1.5 \pm 5.4$ & $3.6 \pm 3.0^{* * *+\S}$ & $-3.4 \pm 3.9 * * *+$ & $-7.3 \pm 6.3 * * *+$ \\
\hline
\end{tabular}

Data are means $\pm \mathrm{SD}$ ( $n=48$ for all series) of the change in left ventricular output over the first and second pairs of cardiac cycles of the inspiratory phase expressed as a percentage of the mean value over the last two cardiac cycles in the end-expiratory phase. $* * * * * *, P<0.01,<0.002,<0.0001$ respectively for significance of percentage change (compared with end-expiratory beats); ${ }^{+}, P<0.0001$ for difference between first and second pair of inspiratory beats; $\&, P<0.001$ for differences between second pairs of hypervolaemia and normovolaemia- 2 and normovolaemia- 2 and hypovolaemia

Table 4. Decrease in pulmonary blood volume during inflation

\begin{tabular}{lll}
\hline & $Q_{\mathrm{p}}$ & $P$ \\
\hline & $\mathrm{ml} \mathrm{kg}^{-1}$ & \\
Normovolaemia-1 & $0.96 \pm 0.17$ & 0.34 \\
Hypervolaemia & $0.61 \pm 0.27$ & 0.000 \\
Normovolaemia-2 & $0.99 \pm 0.24$ & \\
Hypervolaemia & $1.04 \pm 0.17$ & 0.18 \\
\hline
\end{tabular}

Data are means $\pm \mathrm{SD}(n=48$ per series. $P$ values are for paired $t$-test versus normovolaema-2

The tidal loss in flow by inflation, expressed as a percentage of end-expiratory flow, was less when blood volume was increased (Table 2). Thus, the difference between endexpiratory flow and mean flow, which is equal to tidal loss, was relatively larger when blood volume was smaller. Expressed in real flow terms, the tidal loss was the same in hypo- and normovolaemia and was smallest in hypervolaemia (Table 2). Tidal loss can be regarded as a measure of flow modulation. We define modulation as a cyclic fluctuation of constant pattern at constant time intervals, which correspond with the ventilatory cycles in this study.

Why does RV and LV output decrease less during inflation in hypervolaemia (Fig. 2b), than in normo- and hypovolaemia (Figs. $1 \mathrm{~b}$ and $3 \mathrm{~b}$ )? When $P_{\mathrm{cv}}$ increases during inflation, blood accumulates in the venous system. When the venous capacities are loaded to the amount corresponding with the increased $P_{\mathrm{cv}}$ and the increased $P_{\mathrm{cv}}$ is maintained, flow recovers partially to a new stable level but remains lower than before the rise of $P_{\mathrm{cv}}$ [20]. Therefore, we conclude that the smaller decrease in venous return during inflation in hypervolaemia is due to the smaller rise in $P_{\mathrm{cv}}$ (Table 2) and, consequently, to a smaller pooling of blood in the venous capacitance. An additional mechanism might contribute to this smaller pooling during inflation in hypervolaemia, i. e. a higher filling state of the venous system. A higher filling state of the venous system is reflected in the increased $P_{\mathrm{cv}}$ (Fig. $2 \mathrm{c}$ ) and the higher cardiac output (Fig. 2b). In hypo- and normovolaemia, we assume the venous capacitance is in the more compliant and linear part of its vascular $P / V$ relationship, corresponding to general data on vascular capacitance [14]. Then, the same rise in $P_{\mathrm{cv}}$ in hypo- and normovolaemia will lead to accumulation of an equal amount of blood in the venous system, leading to the same tidal loss in flow. In hyper- volaemia, we assume the venous system to be functioning in the less compliant part of the $P / V$ relationship, implying a smaller accumulation of blood for a corresponding rise in $P_{\mathrm{cr}}$.

The tidal loss in flow in real units is the same in hypo- and normovolaemia and smaller in hypervolaemia. This implies that the larger percentage value in hypovolaemia compared with that in normovolaemia merely depends on a lower end-expiratory flow. The use of real flow units tells us more about the behaviour of the system than the percentage changes, which are biased by the changes in end-expiratory flow when the volaemic conditions are changed.

\section{LV output during inflation}

In a previous paper [19], we have considered the effect of squeezing [7] as a main mechanism to explain the delay in LV output with respect to RV output, but we rejected ventricular interdependence and a decrease in afterload on the LV as causal mechanisms. We considered $P_{\mathrm{ao}, \mathrm{tm}}$ as a substitute for LV afterload. Our present data support this interpretation. In early expiration, afterload on the LV decreased hardly at all in hypervolaemia (Fig. 2a) while output was increasing (Fig. 2b), whereas in normovolaemia and hypovolaemia, afterload decreased strongly in the second part of inflation (Fig. $1 \mathrm{a}$ and $3 \mathrm{a}$ ), without any increase in output (Fig. 1b and $3 b$ ).

Besides squeezing, we hypothesize that the mechanical properties capacitance and resistance of the pulmonary vessels are a reason for the maintenance of LV output during early inflation in hypo- and normovolaemia and for its increase in hypervolaemia (Table 3). When input into a capacitance vessel is suddenly stopped, output will decrease exponentially, dependent on capacity and outflow resistance. When the input is decreased gradually, output will decrease more slowly. When a delay in the output of the capacitance vessel occurs and this even increases, as in hypervolaemia, we agree with Jardin et al. [7] and assume that a pressure is acting on the capacity of the pulmonary vessel, i. e. squeezing.

\section{Effects on $Q_{p}$}

The tidal shift in pulmonary blood volume was measured by two different methods: $Q_{\mathrm{p}}^{\prime}$ with EMF and aortic 
flow with pulse contour. To assess whether the difference in methods influenced our results, we compared the tidal changes in $Q_{\mathrm{p}}$ during inflation and expiration and found no significant difference. During haemodynamically stable conditions there should be no difference between blood loss during inflation and recovery during expiration, otherwise either a pooling in or an unloading of the pulmonary circulation would occur. Since we have already demonstrated stable haemodynamic conditions we would have to assume a biased method if we had observed a difference. We conclude that the tidal shift of blood was reliably measured with the two different methods. This reliability was undoubtedly due to calibration of both methods with the same cardiac output estimates found with the use of the method of Fick. This calibration procedure matched both methods.

The decrease in $Q_{\mathrm{p}}$ was the same in normovolaemia and hypovolaemia and was significantly smaller in hypervolaemia (Table 4). Previously we attributed about $7 \%$ of these measured $Q_{\mathrm{p}}$ to changes in LV volume [22]. The similarity of our data in normo- and hypovolaemia indicates that the filling status of the pulmonary circulation is in the linear part of the $P / V$ curve. These data fit with Shoukas' linear model of the pulmonary vascular bed [17]. It is possible that the smaller volume shift in hypervolaemia is due to the fact that the relation between pressure and volume was in the non-linear part of its range, as can be observed in higher filling states and which is in agreement with the mechanical properties of pulmonary vessels [4]. However, $P_{\mathrm{pa}}$ was not much increased after volume loading (Figs. $1 \mathrm{a}$ and $2 \mathrm{a}$ ), which argues against an increased filling state in the arterial part of the pulmonary circulation.

We observed another mechanism which could be a reason for the smaller shift in hypervolaemia, i. e. the smaller fall in input function. In hypo- and normovolaemia, RV output decreased by about the same amount during inflation and the shift of blood volume from the pulmonary circulation was the same. However, in hypervolaemia the input into the pulmonary circulation decreased less during the available time of inflation, which might have caused a smaller shift of $Q_{\mathrm{p}}$, corresponding with the input-output relation of capacitance vessels as mentioned above.

In summary, we conclude that firstly, during inflation in mechanical ventilation, the decrease in $Q_{\mathrm{p}}$ is less in hypervolaemia than it is in normo- and hypovolaemia. This is attributed to a smaller decrease in input into the pulmonary circulation in hypervolaemia. Secondly, the maintenance of LV output when RV output is decreasing during inflation is attributed to the capacitance of the pulmonary vessels in combination with an effect of squeezing on the pulmonary vascular capacity. Thirdly, the tidal loss in flow due to inflation was smaller in hypervolaemia than in normo- and hypovolaemia, where tidal loss is similar. The reasons are a smaller rise in $P_{\mathrm{cv}}$ during inflation in hypervolaemia and possibly a lower capacitance of the systemic venous system if the filling of this is increased. Finally a smaller fall in RV output in hypervolaemia during inflation in concert with a larger fall in $P_{\mathrm{cv}, \mathrm{tm}}$ is attributed to the fact that the RV was on a less steep part of its power/filling pressure relation.

Acknowledgements. The authors thank Mr. A. Drop for his biotechnical assistance and Mr. E. Hoorn for writing the software programs necessary for the beat-to-beat data analyses.

\section{References}

1. Abel FL, Waldhausen JA (1969) Respiratory and cardiac effects on venous return. Am Heart J 78: 266-275

2. Ashbaugh DG, Petty TL, Bigelow DB, Harris TM (1969) Continuous positive pressure breathing (CPPB) in adult respiratory distress syndrome. J Thorac Cardiovasc Surg 5: 95-99

3. Charlier AA, Jaumin PM, Pouleur H (1974) Circulatory effects of deep inspirations, blocked expirations and positive pressure inflations at equal transmural pressures in conscious dogs. J Physiol (Lond) 241: 589-605

4. Harris P, Health D (1986) The human pulmonary circulation, 3rd edn. Churchill Livingstone, London, pp 48-58

5. Hoffman JIE, Guz A, Charlier AA, Wilcken DEL (1965) Stroke volume in conscious dogs: effect of respiration, posture, and vascular occlusion. J Appl Physiol 20: 865-877

6. Jansen JRC, Hoorn E, Goudoever J van, Versprille A (1989) A computerized respiratory system including test functions of lung and circulation. J Appl Physiol 67: 1687-1691

7. Jardin F, Farcot J-C, Gueret P, Prost J-F, Ozier Y, Bourdarius J-P (1983) Cyclic changes in arterial pulse during respiratory support. Circulation 68: 266-274

8. Moreno AH, Burchell AR, Woude R van der, Burke JH (1967) Respiratory regulation of splanchnic and systemic venous return. Am J Physiol 213: 455-465

9. Morgan BC, Martin WE, Hornbein TF, Crawford EW, Guntheroth WG (1966) Hemodynamic effects of intermittent positive pressure respiration. Anesthesiology 27:584-590

10. Morgan BC, Crawford EW, Winterscheid LC, Guntheroth WG (1968) Circulatory effects of intermittent positive pressure ventilation. Northwest Med 67: 149-152

11. Morgan BC, Crawford EW, Guntheroth WG (1969) The hemodynamic effects of changes in blood volume during intermittent positive-pressure ventilation. Anesthesiology 30: $297-305$

12. Nordström L (1972) On automatic ventilation. Part II: Haemodynamic effects of intermittent positive-pressure ventilation with and without an end-expiratory pause. Acta Anaesthesiol Scand [suppl] 47: 29-56

13. Perel A, Piziv R, Cotev S (1987) The systolic pressure variation is a sensitive indicator of hypovolaemia in ventilated dogs subjected to graded hemorrhage. Anesthesiology 67: 498-502

14. Rothe CF (1983) Venous system: physiology of the capacitance vessels. In: Shepherd JT, Abboud FM (eds) The cardiac vascular system, Section II. American Physiological Society, Bethesda, pp 397-452

15. Sarnoff SJ, Berglund E (1954) Ventricular Function. 1. Starling's law of the heart studied by means of simultaneous right and left ventricular function curves in the dog. Circulation 9: $706-718$

16. Schreuder JJ, Jansen JRC, Bogaard JM, Versprille A (1982) Hemodynamic effects of positive end-expiratory pressure applied as a ramp. J Appl Physiol 53: 1239-1247

17. Shoukas AA (1975) Pressure-flow and pressure-volume relations in the entire pulmonary vascular bed of the dog determined by two port analysis. Circ Res 37: 809-818

18. Versprille A (1987) Pulmonary blood flow and blood volume during positive pressure ventilation. In: Vincent JL (ed) Update in intensive care and emergency medicine. Springer, Berlin Heidelberg New York, pp 213-222

19. Versprille A (1990) The pulmonary circulation during mechanical ventilation. Acta Anaesthesiol Scan 34: S94: 51-62 
20. Versprille A, Jansen JRC (1985) Mean systemic filling pressure as a characteristic pressure for venous return. Pflügers Arch 405: 226-233

21. Versprille A, Jansen JRC, Schreuder JJ (1982) Dynamic aspects of the interaction between airway pressure and the circulation. In: Prakash O (ed) Applied physiology in clinical respiratory care. Nijhoff, The Hague, pp 447-463

22. Versprille A, Jansen JRC, Frietman RC, Hlusmann AR, Klauw MM v d (1990) Negative effect of insufflation on cardiac output and pulmonary blood volume. Acta Anaesthesiol Scand 34: $607-615$
23. Wesseling KH, Wit B de, Weber JAP, Smith N Ty (1983) A simple device for the continuous measurement of cardiac output. In: Ghista DN (ed) Advances in cardiovascular physiology. Karger, Basel, pp 16-52

24. Wong M, Escobar EE, Martinex G, Butler J, Rapaport E (1967) Effect of continuous pressure breathing on right ventricular volumes. J Appl Physiol 22: 1053-1060

25. Young DB (1975) Neural control of fluid volumes: volume receptors and autonomic control. In: Guyton AC, Taylor AC, Granger HJ (eds) Circulatory physiology II: Dynamics and control of body fluids. Saunders, Philadelphia, pp 262-273 